The territory of malingering and illness deception is one of the last 'no go' areas in medical practice: few doctors tread there with any degree of confidence, and little is taught about it to medical students or postgraduate trainees. The authors of this book have therefore taken on a difficult challenge. Malingering has been neglected in the medical literature, probably because it is not regarded as a medical diagnosis in the broadest sense of the term. Neither of the widely used medical and psychiatric classifications regard malingering as a valid diagnosis. It is, essentially, a conclusion that is reached after relevant medical and psychiatric disorders have been excluded. Although it is therefore not a medical condition, malingering impinges on medical practice in most areas of clinical medicine. It implies deliberate deception and in this context the clinician has to make judgements about the level of conscious awareness, the degree of free will and the motivation that accompanies the spurious symptoms of ill-health. The conclusion that someone is malingering carries highly pejorative judgements. There are serious implications for the doctor if the diagnosis is incorrect, with medico-legal consequences and professional reprimands.

The book makes it clear that malingering is on the increase. The contributors cite various examples, including sickness absence, early retirement on grounds of ill-health, health insurance fraud and bogus personal injuries compensation. The assessment of malingering is complicated by observations that suggest that even within the same individual conscious awareness is not an all-or-none phenomenon. It varies over time and its assessment is highly subjective. Only when there is direct, recorded observation that an individual is able to perform activities that he or she has claimed not to be able to perform can malingering be concluded with a reasonable degree of certainty.

In their opening chapter the authors provide a helpful definition of malingering, which they describe as a conscious voluntary act or set of actions made with the intention of obtaining personal advantage by securing benefits and/or lack of responsibilities that society and the legal system have bestowed upon the sick role. Several of the subsequent chapters approach malingering from a sociological viewpoint. Others attempt to define the boundary between malingering and psychiatric illness, particularly dissociative disorders (hysteria) and functional somatic syndromes. There is a very useful section on the medico-legal and occupational perspectives. Particularly intriguing are two chapters that review attempts to distinguish malingering from dissociative disorder, using functional brain imaging. This work is at a preliminary stage and remains inconclusive, but it does open up the possibility of obtaining objective criteria to distinguish symptoms associated with loss of free will from those that appear to be consciously determined.

Doctors, whatever their specialty, like to believe that patients who consult them are honest, distressed and in need of medical help. The notion that some people wilfully set out to deceive doctors sits uncomfortably with this assumption. This book provides an illuminating glimpse into the hinterland between illness and fraudulent behaviour. It is a book that should have relevance to clinicians whatever their background, to the legal profession and to those who have an interest in understanding human behaviour in relation to health.

Geoffrey Lloyd Consultant Liaison Psychiatrist, Royal Free Hospital, London NW3 2QG, UK

\section{Unipolar Depression: A Lifespan Perspective}

Edited by lan M. Goodyer. Oxford: Oxford University Press. 2003. 224 pp. $€ 24.95$ (pb). ISBN 0198510950

Are there important continuities between depressive episodes in childhood, adolescence, young adulthood, middle age and later life? Is the categorisation of depression by the age of the sufferer a reflection of the division of the Royal College of Psychiatrists into child, adult and old age faculties? Or are there genuine differences in aetiology, pathogenesis, clinical features, response to treatment and outcome for each life stage? Will an examination of the continuities and dislocations of these dimensions in relation to a person's life history be illuminating, or will it lead us into a conceptual morass?

Professor Goodyer brings the developmental perspectives of child psychiatry to one of the most pervasive and cumulatively disabling of mental disorders. He has commissioned six concise and expert reviews of our knowledge about depression at each life stage. These are sandwiched between two editorials, which try to move towards inclusion and integration of the developmental concepts of human growth and ageing. A third of the book's 200 or so pages are taken up by references. The chapter by Birmaher \& Rozel covers childhood depression in just 10 pages, stressing the importance of comorbidity and complex psychosocial environments for this group. Harrington gives a masterly but necessarily skeletal review of research into every aspect of adolescent depression. Paykel \& Kennedy provide an excellent but painfully condensed 15 pages covering depression between the ages of 40 and 60 , and O'Brien $\&$ Thomas offer a fascinating summary of depressive disorders in later life, highlighting the increasing role of neurobiological changes in risk processes at this time.

There may have been variable latitude in the brief given to authors: for example, Lewinsohn \& Seely, writing under the heading of 'early adult life', devote all of their 22 pages to their own Oregon Adolescent Depression project. Depression between the ages of 25 and 40 meets a cruel fate, having no coverage at all. In a chapter entitled 'Intergenerational transmission', Murray \& Cooper document the impact of maternal depression on infant and child development, but their focus is on cognitive and behavioural outcomes rather than on depressive disorder in the offspring.

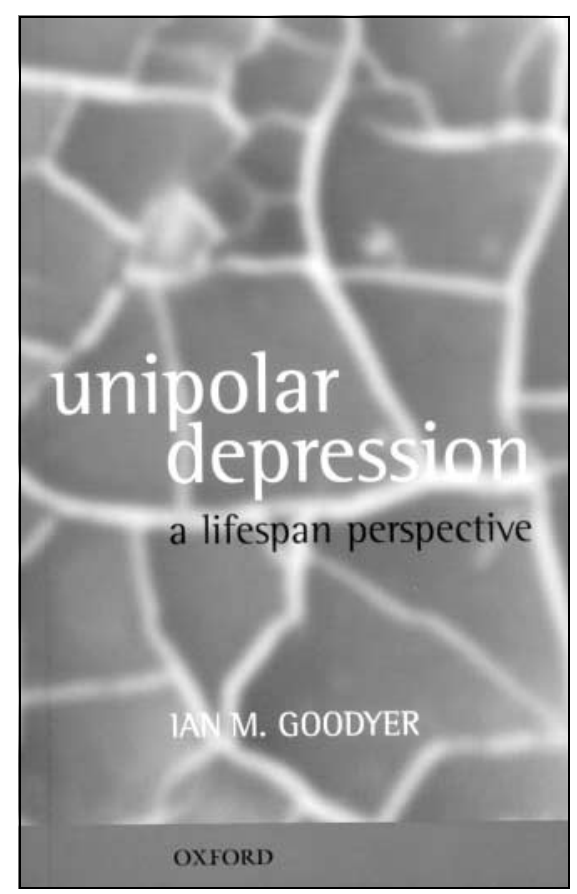


The most compelling parts of this book are the detailed accounts of the rare longitudinal cohort studies that examine transitions across life-span boundaries; illustrating the differences between risk processes at first onset and recurrence, and introducing the concept of critical periods for the activation and interaction of risk factors in biological and psychosocial domains.
Does Goodyer's strategy work? The answer may depend on the life-span perspective of the reader. Child psychiatrists will be pleased with the detailed treatment of their field and the useful (if extremely condensed) reviews of depression in other age groups. Adult and old age psychiatrists may be frustrated by this condensation, and by their own lack of sophisticated understanding of technical issues in the earlier chapters. Those who succeed in keeping the full breadth of material in focus will be rewarded by glimpses of the power of the life-span approach - which, it seems to me, is an idea whose time has finally come.

Alan Lee Consultant in General Adult Psychiatry and Senior Lecturer, Department of Psychiatry, B Floor, South Block, University Hospital, Nottingham NG7 2UH, UK 